440

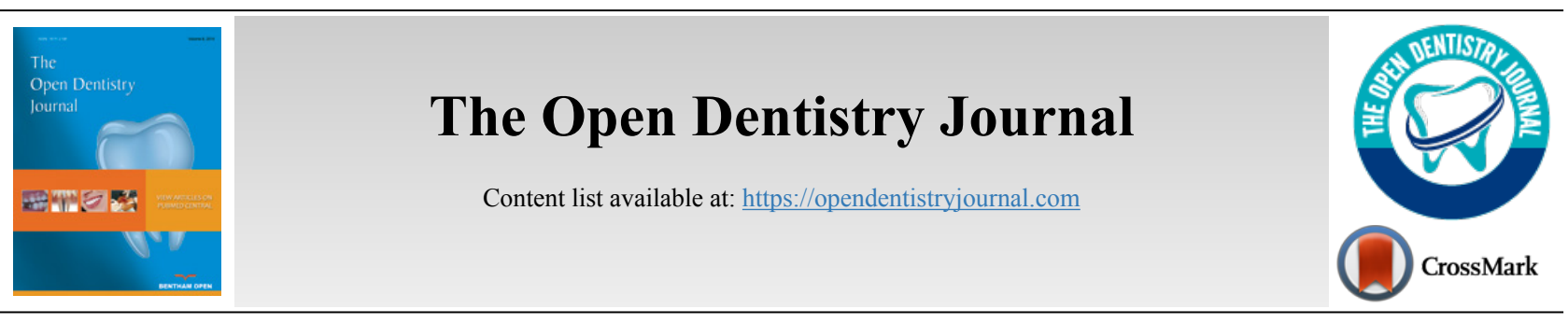

RESEARCH ARTICLE

\title{
Knowledge, Attitudes and Practice of Dental Implants among Dental Interns in Saudi Arabia - A Cross-Sectional Study
}

\author{
Khaled Alzahrani ${ }^{1, *}$, Abdulrahman Mohammed Alnafisah ${ }^{2}$, Khalid Gohormallah Alzahrani ${ }^{2}$ and Khalid Ghalib Alharbi ${ }^{2}$ \\ ${ }^{1}$ Department of Prosthodontics Sciences, Prince Sattam Bin Abdulaziz University Al Kharj, P.O. Box 173 Ad Dilam Rd Al Kharj, 16278 Saudi Arabia \\ ${ }^{2}$ College of Dentistry, Prince Sattam Bin Abdulaziz University, Alkharj, Saudi Arabia
}

\begin{abstract}
:
Objective:

The aim of the study is to assess knowledge, attitude and practices of dental implants among dental interns in Saudi Arabia

Materials and Methods:

A self-designed, close-ended questionnaire was distributed among 205 interns chosen by stratified random sampling technique. The questionnaire consisted of 28 items pertaining to demographic characteristics, knowledge and practices of dental implants. Responses were coded and entered into spreadsheet software (Microsoft Excel 16.0.) and analyzed using Statistical Package for Social Sciences (SPSS, IBM Version 22.0) and contingency tables and chi-square test $(\chi 2)$.

\section{Results:}

The majority of the participants were males (64.4\%), between $24-26$ years of age (64\%) and had a GPA between $4-5$ (63.4\%). The majority of the participants gained knowledge of dental implants through theoretical lectures $(98.5 \%)$, and most of them ( $80 \%)$ knew, what material, an implant was made up of. Almost all participants $(91.7 \%)$ knew that dental implants had surface modifications. Most (64.4\%) believed that case selection is the most important criteria for the success of dental implant therapy, and this differed significantly among participants with respect to GPA $(p=0.03)$. Many participants $(60 \%)$ believed that the most important advantage of dental implants over fixed prosthesis is that reduction of adjacent tooth is not needed, and this differed significantly between males and females $(p=0.026)$. There was a significant difference ( $p<0.001)$ between males and females when it came to confidence in independently restoring teeth using dental implants. $63 \%$ of the participants were confident to use dental implants in their future practice.

\section{Conclusion:}

Knowledge of dental implants among dental interns is satisfactory, but this study reveals that participants lack practical experience and would like to acquire more clinical skills.

\section{Limitations:}

The response rate of participants from each university was low, which made comparisons between different universities difficult because sample size from some universities was very small, which could not produce statistically accurate results.
\end{abstract}

Keywords: Dental implant, Eduction, Dental intern, GPA, Knowledge, Attitudes.

\section{Article History}

Received: March 25, 2020

Revised: July 1, 2020

Accepted: July 15, 2020

\section{INTRODUCTION}

A dental implant is a prosthetic replacement for a natural tooth root, which is surgically placed into the jaw at the site of a missing tooth that may have been lost due to trauma, periodontal disease, infections, tumors and development

\footnotetext{
* Address correspondence to this author at Department of Prosthodontics Sciences, Prince Sattam Bin Abdulaziz University Al Kharj, P.O. Box 173 Ad Dilam Rd Al Kharj, 16278 Saudi Arabia; Tel: +966554176226;

E-mail:drkmq@hotmail.com
}

anomalies [1]. They were initially used to restore completely edentulous arches and exhibited improved retention, stability and functional efficiency of complete dentures and also improved the quality of life of patients [2 4]. As long term, multicenter studies reported excellent survival rates in partially edentulous arches and for single tooth replacements [5 - 7], dental implants were gradually integrated as routine treatment options for single tooth replacements and partial edentulism so much so that they have become one of the 
most important treatment modalities to restore esthetics and function in completely or partially edentulous arches. In addition to having high success rates and highly predictable treatment outcomes, dental implants conserve the alveolar bone and adjacent tooth structure, which has only added to their popularity and acceptance among patients [8].

Various studies have reported that patients are highly amenable to dental implant treatment. Grogono et al. (1989) reported significantly greater patient satisfaction with dental implants as compared to conventional dentures as well as overall improved confidence and oral health [9]. Walia et al. (2016) also reported that pre-treatment expectations of patients were fulfilled, and they were satisfied with dental implants [10]. Reports like these have encouraged practitioners to make them mainstream in their practice, but until the last decade, dental implant treatment was fairly restricted to specialists [11]. Currently, there has been a surge in interest for dental implants among general dental practitioners as well, who have been vying to train themselves in this treatment modality and expand their skill set [11]. This calls for an increase in implant theory, clinical and didactic training in pre-doctoral and undergraduate dental education. Although the curriculum guidelines for undergraduate training in implant dentistry were established by the American Association of Dental Schools in the 1990s [12], surveys in the US showed that colleges only gradually incorporated didactic instructions in implant dentistry into their curriculum from $33 \%$ of colleges in 1974 [13], to $73 \%$ in 1990 [14] to $86 \%$ in 1995 [15] to $89 \%$ in 1997 [16] and to $97 \%$ in 2006 [17, 18]. In Europe, dental implants were even more slowly incorporated into mainstream curriculum, with $10 \%$ of schools offering dental implant courses before 1990 and gradually rising to $80 \%$ in early $2000 \mathrm{~s}^{19}$. Even until 2010 , the worldwide pre-doctoral implant training was reported to be only $69 \%$ of schools surveyed [19]. This shows that there are still institutions and colleges that have not integrated dental implant education into their curriculum.

There have not been many qualitative or quantitative studies in Saudi Arabia that depict a clear picture of dental implant education across universities in the country. A study by Alkindi et al. (2016) tried to evaluate the current status of dental implant education in Saudi Arabia by surveying five program directors in charge of undergraduate dental education and interns in 6 different dental schools. The study revealed that dental implant education varied greatly between schools. One important finding was that program directors in these institutes felt confident that fresh graduates from their universities were capable of restoring simple cases using dental implant therapy [11]. Another study conducted by Aljohani and Alghamdi (2009) tried to assess pre-doctoral dental implant education in a university in Saudi Arabia by surveying dental interns and assessing their knowledge [20]. Both these studies collectively reported from 6 dental institutions out of around 27 institutions with undergraduate dental training programs. The present study aims to expand to all these institutions and is a multi-center study that aims to assess the knowledge, attitudes and practices of dental implant therapy among dental interns in all the institutions of Saudi Arabia. It is also among the primary objectives of this research to find out if any differences exist in the knowledge, attitudes and practice of dental interns with respect to age, gender and their final grades with the primary assumption that no difference exists among the various groups. It is hoped that through the results of this extensive study, program directors in various institutions in Saudi Arabia, as well as policymakers, will be able to point out areas of improvement in dental implant training for undergraduate students.

\section{MATERIALS AND METHODS}

\subsection{Study Design}

The present research is a cross-sectional study proposed to the Institutional Review Board (IRB) of Prince Sattam bin Abdulaziz University with IRB number PSAU2020014. This research has been reported according to the STROBE guidelines for reporting cross-sectional studies.

\subsection{Sample}

A random, stratified sampling method was used to obtain a sample from among dental interns in all universities in Saudi Arabia. The sample size was estimated using the following formula: $\mathrm{n}=\mathrm{Z}_{1-\alpha / 2}[\mathrm{p}(1-\mathrm{p})] / \mathrm{d}^{2}$

Where,

$\mathrm{n}$ is the sample size,

$\mathrm{Z}_{1-\alpha / 2}{ }^{2}$ is the standard normal variate (at 5\% Type 1 error and $95 \% \mathrm{CI}[p<0.05]$ it is 1.96$)$,

$\mathrm{p}$ is the expected proportion in population-based on previous studies and,

$\mathrm{d}$ is the absolute error or precision.

According to this formula, with a present knowledge level of $85 \%$ based on previous studies and a precision of $5 \%$, a minimum sample of 195 dental interns were needed to produce statistically accurate results

\subsection{Questionnaire}

A self-designed, close-ended questionnaire was administered to the study sample. The questionnaire was validated with face validity and content validity and tested for inter-reader reliability and Cronbach's alpha testing. The questionnaire consisted of 28 questions, which were informally arranged into three sections; demographic information, questions assessing knowledge of dental implants, and questions pertaining to practices in dental implants.

\subsection{Data Analysis}

Responses were entered into spreadsheet software (Microsoft Excel 16.0.) and frequency distribution was calculated. Descriptive statistics were used to calculate means and standard deviations. Inferential statistical analysis was done using Statistical Package for Social Sciences (SPSS, IBM Version 22.0). Contingency tables and chi-square test $\left(\chi^{2}\right)$ were used to determine whether there were any correlations between correct responses to the knowledge variables and participant demographics. 


\section{RESULTS}

A total of 205 interns from different dental schools responded to the questionnaire. First, general information about the demographic characteristics of the participants is collected and analyzed. The descriptive analysis, which is shown in Table 1, indicates that around $64.4 \%$ of the participants were male. Around $64 \%$ of the participants were between 24 and 26 years old, while $33 \%$ were between 22 and 24 years old. In addition, the grade point average (GPA) of the participants was collected. The results show that $63.4 \%$ of participants in this survey had a GPA between 4 and 5, while $35.1 \%$ a GPA of $3-$ 4.

\section{ANALYSIS OF THE SURVEY}

In the first step, the frequency of the responses for each question is extracted and illustrated in Table A1. Next, the ChiSquare test is performed to investigate the differences between demographic categories in their response to the survey. The relationship between each question and the categories (Age, Gender, GPA) is separately investigated.

Table 1. Results of the intergroup comparability of the sex distribution (Fisher's exact test).

\begin{tabular}{|c|c|c|}
\hline \multicolumn{3}{|c|}{ Frequency of demographic characteristics } \\
\hline & Frequency & $\%$ \\
\hline \multicolumn{3}{|l|}{ GENDER } \\
\hline Female & 73 & 35.6 \\
\hline Male & 132 & 64.4 \\
\hline \multicolumn{3}{|l|}{ AGE } \\
\hline $22-24$ & 67 & 32.7 \\
\hline $24-26$ & 131 & 63.9 \\
\hline $26-28$ & 7 & 3.4 \\
\hline \multicolumn{3}{|l|}{ GPA } \\
\hline $2.0-3.0$ & 3 & 1.5 \\
\hline $3.0-4.0$ & 72 & 35.1 \\
\hline $4.0-5.0$ & 130 & 63.4 \\
\hline
\end{tabular}

Table A1. Frequencies of responses to the questions and respective $\chi 2$ test for determination of differences between Age, Gender and GPA groups.

\begin{tabular}{|c|c|c|c|c|c|}
\hline \multirow[t]{2}{*}{ QUESTIONS } & \multirow{2}{*}{ Frequency } & \multirow[t]{2}{*}{$\%$} & \multicolumn{3}{|c|}{$\chi^{2}$ (p-value) } \\
\hline & & & Gender & Age & GPA \\
\hline \multicolumn{6}{|c|}{ 2- What was the mode of learning? } \\
\hline Theoretical/lectures & 202 & 98.5 & $1.281(0.258)$ & $1.720(0.423)$ & $1.756(0.416)$ \\
\hline Laboratory training & 20 & 9.7 & $0.004(0.952)$ & $1.173(0.556)$ & $2.729(0.256)$ \\
\hline Surgical assisting & 15 & 7.3 & $0.136(0.712)$ & $0.700(0.705)$ & $1.110(0.574)$ \\
\hline Surgical observation & 23 & 11.2 & $1.686(0.194)$ & $0.541(0.763)$ & $0.524(0.769)$ \\
\hline Prosthodontic observation & 11 & 5.3 & $0.491(0.483)$ & $1.304(0.521)$ & $0.668(0.716)$ \\
\hline Clinical training & 9 & 4.3 & $0.320(0.571)$ & $0.822(0.663)$ & $0.890(0.641)$ \\
\hline \multicolumn{6}{|c|}{ 3-From what year onwards did you start studying about dental implants in your university? } \\
\hline Year 2 onwards & 8 & 3.9 & $19.317(0.001)$ & $20.584(0.008)$ & $9.006(0.342)$ \\
\hline Year 3 onwards & 11 & 5.4 & & & \\
\hline Year 4 onwards & 26 & 12.7 & & & \\
\hline Year 5 onwards & 107 & 52.2 & & & \\
\hline Year 6 only & 53 & 25.9 & & & \\
\hline \multicolumn{6}{|c|}{ 4-What primary material is a dental implant made of? } \\
\hline All of the above & 38 & 18.5 & $2.026(0.567)$ & $8.245(0.221)$ & $11.176(0.083)$ \\
\hline Cobalt & 1 & 0.5 & & & \\
\hline Stainless steel & 2 & 1 & & & \\
\hline Titanium & 164 & 80 & & & \\
\hline \multicolumn{6}{|c|}{ 5-Are you aware that a dental implant body has different designs? } \\
\hline No & 11 & 5.4 & $0.003(0.957)$ & $0.643(0.725)$ & $4.202(0.122)$ \\
\hline
\end{tabular}




\begin{tabular}{|c|c|c|c|c|c|}
\hline Yes & 194 & 94.6 & & & \\
\hline \multicolumn{6}{|c|}{ 6-If yes, which of the following is an example of a dental implant body design? } \\
\hline All of the above & 140 & 68.3 & $1.285(0.733)$ & $4.475(0.613)$ & $7.225(0.301)$ \\
\hline Cylindrical & 45 & 22 & & & \\
\hline Hollow & 3 & 1.5 & & & \\
\hline Screw shaped & 17 & 8.3 & & & \\
\hline \multicolumn{6}{|c|}{ 7-Are you aware that dental implants have surface modifications? } \\
\hline No & 17 & 8.3 & $0.311(0.577)$ & $4.172(0.124)$ & $4.008(0.135)$ \\
\hline Yes & 188 & 91.7 & & & \\
\hline \multicolumn{6}{|c|}{ 8-What do you think is the most important factor for implant success? } \\
\hline Case selection & 132 & 64.4 & $2.734(0.741)$ & $9.931(0.447)$ & $19.943(0.030)$ \\
\hline Don't know & 12 & 5.9 & & & \\
\hline Experience of the operator & 9 & 4.4 & & & \\
\hline Implant type and material & 27 & 13.2 & & & \\
\hline Patient compliance & 18 & 8.8 & & & \\
\hline Surgical technique & 7 & 3.4 & & & \\
\hline \multicolumn{6}{|c|}{ 9-What do you think is the main advantage of dental implants over other fixed prosthesis? } \\
\hline Better aesthetics & 13 & 6.3 & $9.261(0.026)$ & $22.115(0.001)$ & $4.655(0.589)$ \\
\hline Don’t know & 2 & 1 & & & \\
\hline Lasts longer & 67 & 32.7 & & & \\
\hline More conservative; eliminates the need for adjacent tooth reduction & 123 & 60 & & & \\
\hline \multicolumn{6}{|c|}{ 10-Have you attended any continuing education courses on dental implants? } \\
\hline No & 137 & 66.8 & $0.059(0.808)$ & $7.136(0.028)$ & $2.532(0.282)$ \\
\hline Yes & 68 & 33.2 & & & \\
\hline \multicolumn{6}{|c|}{ 11-Have you suggested dental implants to any of your full/partially edentulous patients? } \\
\hline No & 23 & 11.2 & $1.025(0.311)$ & $2.029(0.363)$ & $1.785(0.410)$ \\
\hline Yes & 182 & 88.8 & & & \\
\hline \multicolumn{6}{|c|}{ 12-If no, what are the reasons you did not suggest dental implant treatment to your patients? } \\
\hline Overall treatment duration & 9 & 12.2 & $4.613(0.329)$ & $6.224(0.622)$ & $14.906(0.061)$ \\
\hline Patient unavailability & 5 & 6.8 & & & \\
\hline Shortage of trained supervisors/faculty & 8 & 10.8 & & & \\
\hline Treatment cost & 52 & 70.3 & & & \\
\hline \multicolumn{6}{|c|}{ 13-Do you think restoring missing teeth with dental implants requires a multi-disciplinary approach? } \\
\hline No & 13 & 6.3 & $0.049(0.824)$ & $1.197(0.550)$ & $4.324(0.115)$ \\
\hline Yes & 192 & 93.7 & & & \\
\hline \multicolumn{6}{|c|}{ 14-Have you surgically placed dental implants in your university independently? } \\
\hline No & 191 & 93.2 & $2.625(0.105)$ & $2.323(0.313)$ & $0.883(0.643)$ \\
\hline Yes & 14 & 6.8 & & & \\
\hline \multicolumn{6}{|c|}{ 15-If yes, how many? } \\
\hline $1-3$ & 12 & 75.0 & $7.677(0.053)$ & $5.465(0.486)$ & $6.326(0.388)$ \\
\hline $3-6$ & 2 & 12.5 & & & \\
\hline More than 9 & 2 & 12.5 & & & \\
\hline \multicolumn{6}{|c|}{ 16-Did you also place restorations over the dental implants you placed surgically? } \\
\hline No & 194 & 94.6 & $4.020(0.134)$ & $6.679(0.154)$ & $1.337(0.855)$ \\
\hline Yes, placed restorations on all of them & 9 & 4.4 & & & \\
\hline Yes, placed restorations on some of them & 2 & 1 & & & \\
\hline \multicolumn{6}{|c|}{ 17-Do you think dental implants are unaffordable for most patients? } \\
\hline No & 75 & 36.6 & $1.260(0.262)$ & $1.699(0.428)$ & $2.956(0.228)$ \\
\hline Yes & 130 & 63.4 & & & \\
\hline \multicolumn{6}{|c|}{ 18-Do you think dental implants require additional oral hygiene care and maintenance by the patient and dentist? } \\
\hline No & 8 & 3.9 & $1.939(0.164)$ & $4.703(0.095)$ & $0.541(0.763)$ \\
\hline Yes & 197 & 96.1 & & & \\
\hline \multicolumn{6}{|c|}{ 19-Do you think dental implants can have technical and biological complications? } \\
\hline No & 3 & 1.5 & $0.564(0.754)$ & $9.549(0.049)$ & $3.225(0.521)$ \\
\hline Yes & 201 & 98.5 & & & \\
\hline
\end{tabular}


(Table $\$ \square$ ) contd.....

\begin{tabular}{|c|c|c|c|c|c|}
\hline \multicolumn{6}{|c|}{ 20-Are you confident to independently restore teeth using dental implants in your future practice? } \\
\hline No & 75 & 36.6 & $21.445(<0.001)$ & $8.607(0.014)$ & $4.558(0.102)$ \\
\hline Yes & 130 & 63.4 & & & \\
\hline \multicolumn{6}{|c|}{ 21-Will you offer dental implant therapy as a treatment option in your future practice? } \\
\hline Don’t know yet & 30 & 14.6 & $1.086(0.581)$ & $22.358(<0.001)$ & $8.552(0.073)$ \\
\hline No & 23 & 11.2 & & & \\
\hline Yes & 152 & 74.1 & & & \\
\hline \multicolumn{6}{|c|}{ 22-If no, why? } \\
\hline I am not confident to perform implant surgeries yet & 24 & 50.0 & $3.082(0.544)$ & $2.059(0.979)$ & $5.849(0.664)$ \\
\hline I am not interested in dental implant therapy & 14 & 29.2 & & & \\
\hline More time consuming than other procedures & 4 & 8.3 & & & \\
\hline Not cost-effective & 6 & 12.5 & & & \\
\hline \multicolumn{6}{|c|}{$\begin{array}{l}\text { 23-In your opinion, and based on your experience, what areas of undergraduate implant dentistry education need improvement? (Select all } \\
\text { that apply) }\end{array}$} \\
\hline More clinical training needed & 27 & 13.2 & $6.213(0.623)$ & $14.910(0.531)$ & $15.096(0.518)$ \\
\hline More laboratory training needed & 11 & 5.4 & & & \\
\hline More laboratory training needed, More clinical training needed & 69 & 33.7 & & & \\
\hline More lectures needed & 7 & 3.4 & & & \\
\hline More lectures needed, More clinical training needed & 6 & 2.9 & & & \\
\hline More lectures needed, More laboratory training needed & 5 & 2.4 & & & \\
\hline $\begin{array}{l}\text { More lectures needed, More laboratory training needed, More clinical } \\
\text { training needed }\end{array}$ & 66 & 32.2 & & & \\
\hline No changes needed & 14 & 6.8 & & & \\
\hline * Green numbers indicate significant differences & & & & & \\
\hline
\end{tabular}

As shown in Table 2, the majority of the participants obtained knowledge of dental implants through theoretical lectures $(98.5 \%)$, while very few of them $(9.7 \%)$ received laboratory training and even fewer through surgically assisting (7.3\%). Only $4.3 \%$ participants received clinical training in dental implants, but these differences were not statistically significant across age, gender or GPA. More than half of the participants received dental implant education from Year 5 onwards (52.2\%) followed by Year 6 onwards $(25.9 \%)$, and the response was significantly different across gender $\left(\chi^{2}=19.317\right.$, $\mathrm{p}=0.001)$. Significantly more Females pointed out that they start studying about dental implants from year 4 onwards, while more males started studying dental implants from year 5 onwards (Fig. 1).

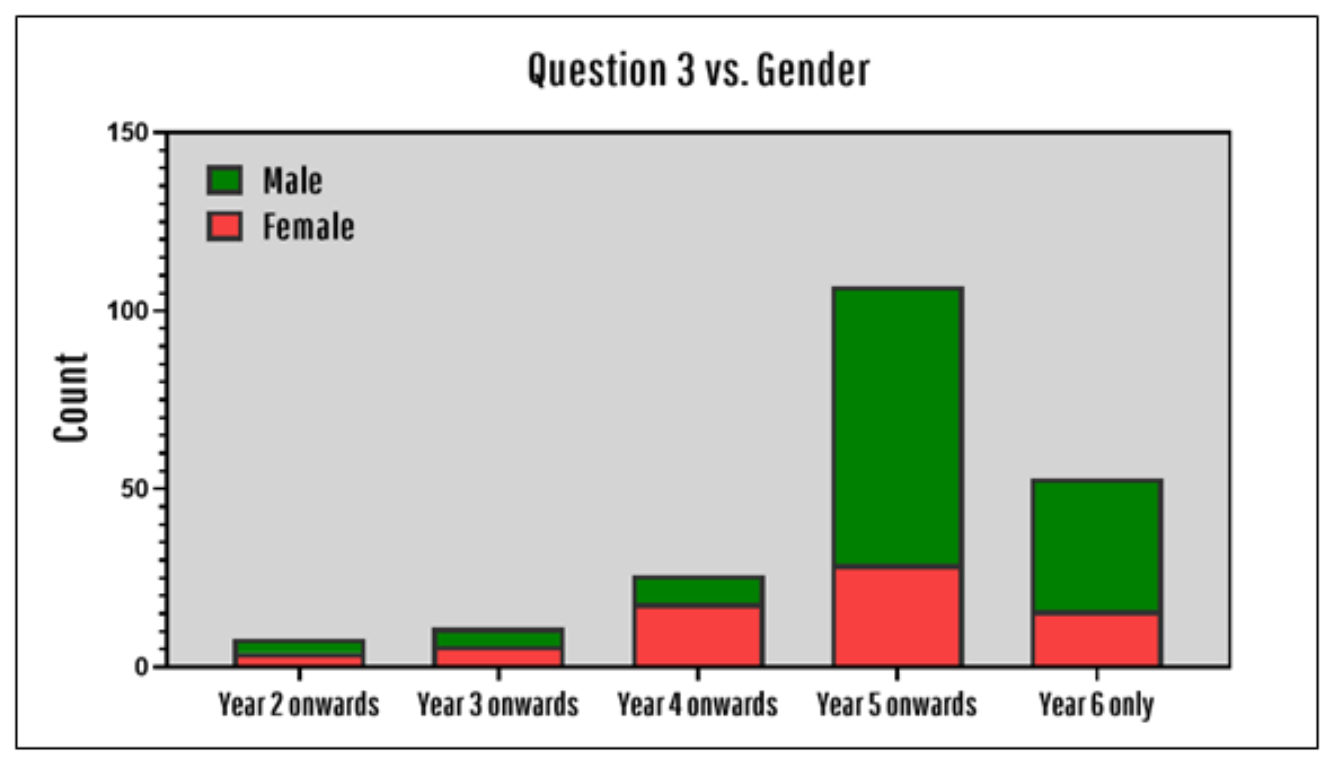

Fig. (1). From what year onwards did you start studying about dental implants in your university? 


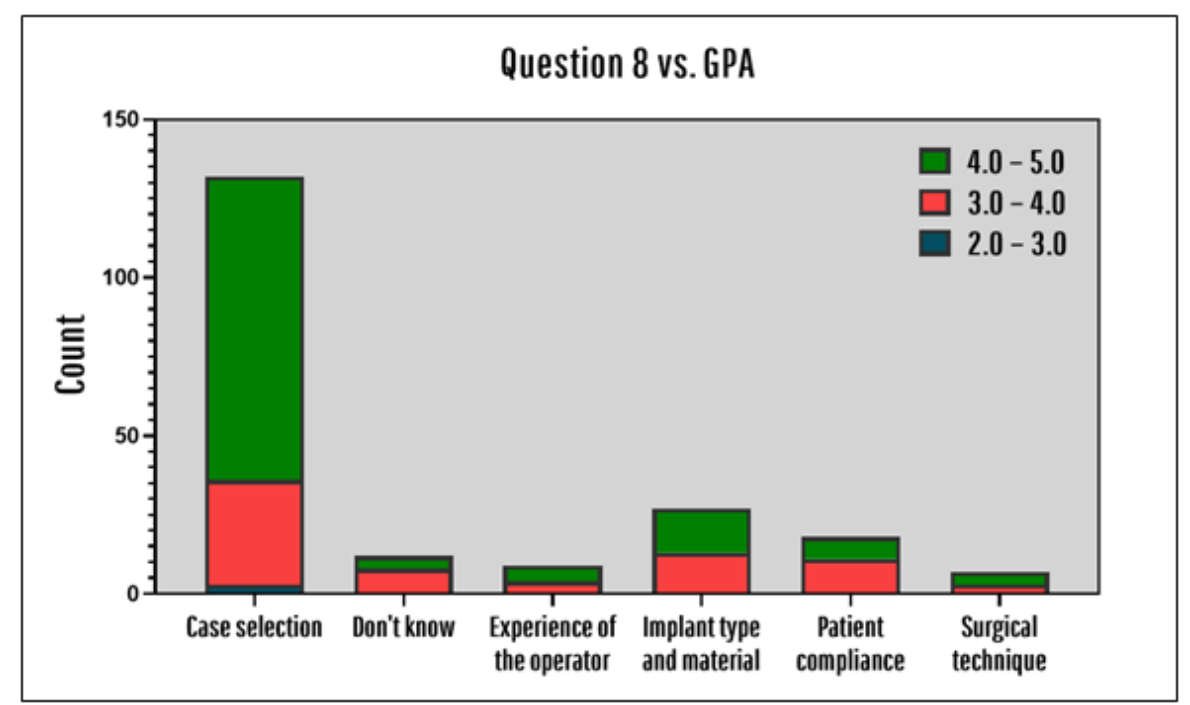

Fig. (2). What do you think is the most important factor for implant success?

$80 \%$ of all participants knew what a dental implant is primarily made up of (which is titanium) and no significant difference was observed in this regard among different age, gender or GPA groups. All groups also seemed to be similarly knowledgeable about dental implants having surface modifications (91.7\%). 64.4\% of the participants believed that case selection is the most important factor for implant success. However, this belief is significantly different in different GPA groups $\left(\chi^{2}=19.943, p=0.030\right)$. As shown in Fig. (2), significantly more participants with grade point average between 4.0 and 5.0 believe that case selection is the most important factor for implant success than other GPA groups $(\mathrm{RR}=1.56,95 \%$ CI $1.29,1.83)$

$60 \%$ of the interns believed that the main advantage of dental implants over other fixed prosthesis is the elimination of the need for adjacent tooth reduction, while $32.7 \%$ believed that the main advantage is that they last longer than other fixed prostheses. More males than females believe that the main advantage of the dental implant is that they last longer $(\mathrm{RR}=$ $1.34,95 \%$ CI $\left.1.14,1.52, \chi^{2}=9.261, p=0.026\right)$, as shown in Fig. (3) and this difference is statistically significant. In addition, interns between 24 and 26 years old chose "lasts longer" option much more than the other age groups $\left(\chi^{2}=\right.$ 22.115, $\mathrm{p}=0.001)$.

Among the interns participated in this survey (Fig. 4), only $33.2 \%$ attended continuing education courses, and interns who were 22-24 years old had much lower participation in continuing education courses than those interns between 24 and 26 years old $\left(\chi^{2}=7.136, \mathrm{p}=0.028\right)$.

In addition, $98.5 \%$ of all the interns in this survey believed that dental implants can have technical and biological complications, the majority of whom $(63.7 \%)$ have an age between 24 and 26 years old $\left(\chi^{2}=9.549, \mathrm{p}=0.049\right)$.
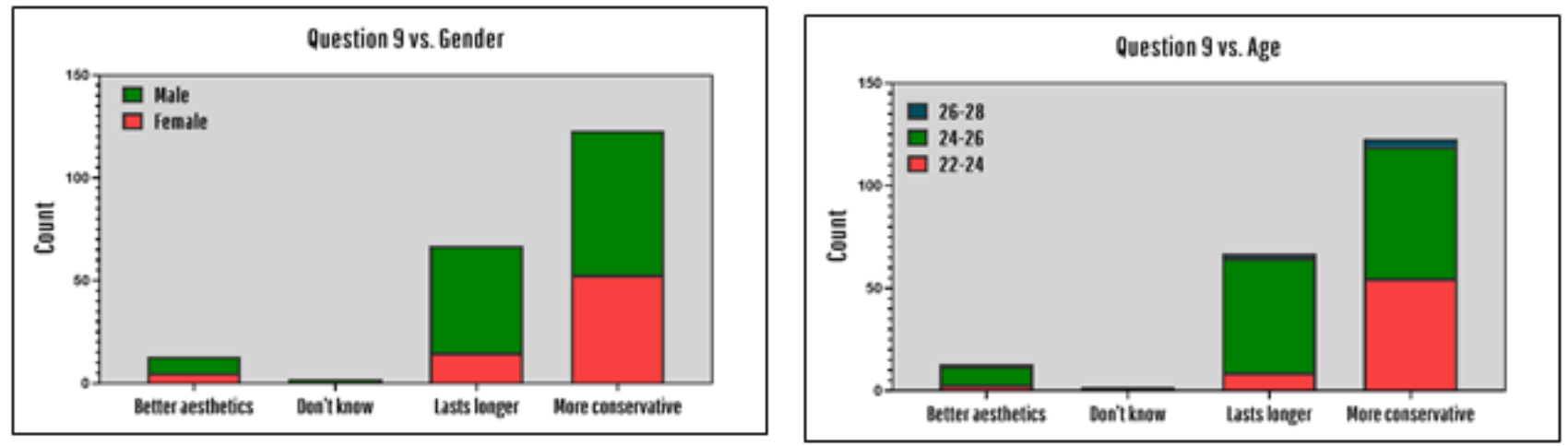

Fig. (3). What do you think is the main advantage of dental implants over other fixed prosthesis? 


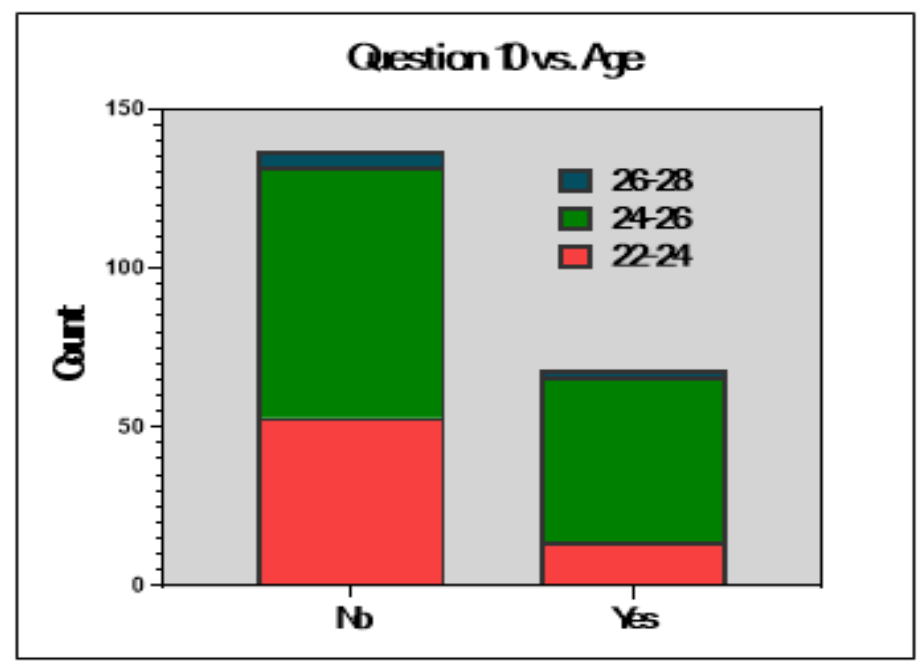

Fig. (4). Have you attended any continuing education courses on dental implants?

Some additional results which could be extracted from this survey are the different levels of confidence of independently restoring teeth between females and males $\left(\chi^{2}=21.445, \mathrm{p}<\right.$ 0.001). The results indicated that males seem to be significantly more confident about their ability to independently restore teeth using dental implants (Fig. 5). It should also be mentioned that around $63 \%$ of all interns were confident about using dental implants in their future practice, and interns between the age of 24 and 26 years seemed to be significantly more confident than the other age groups $\left(\chi^{2}=\right.$
$8.607, \mathrm{p}=0.014) .74 \%$ of the participants stated that they will offer dental implant therapy as a treatment option in their future practice (Fig. 5).

Finally, as shown in Table A2, it is illustrated that the level of knowledge and practice in all demographic groups are not significantly different from each other, however, the attitude of dental interns with average grades of $4.0-5.0$ has the most positive attitude towards offering tooth implant as a treatment option $(\mathrm{F}=3.325, \mathrm{p}=0.038)$.
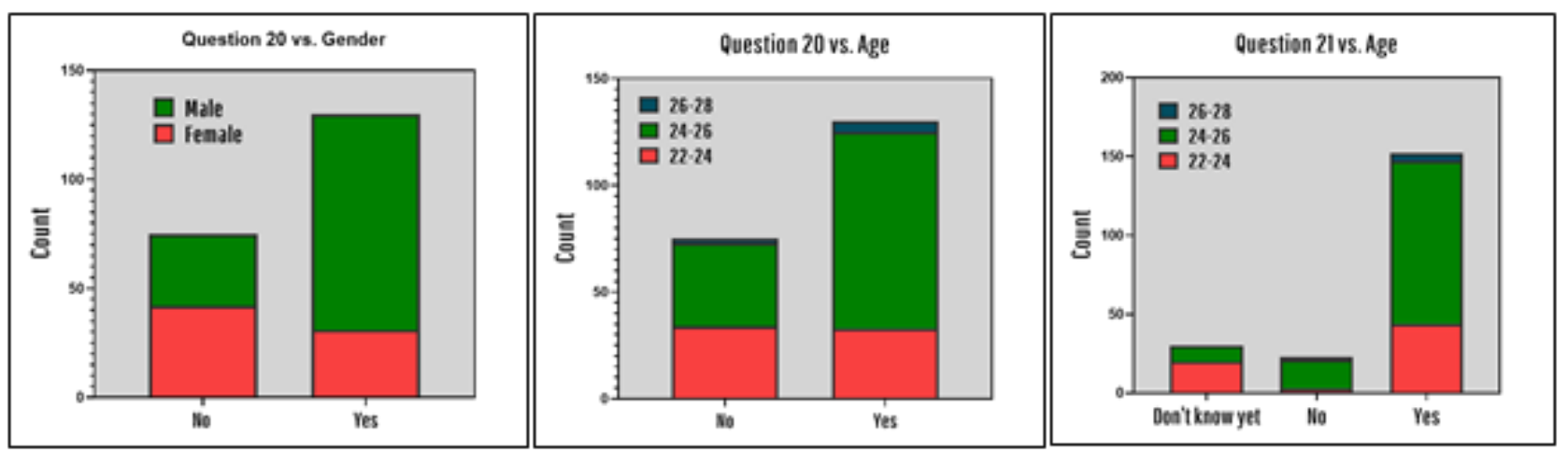

Fig. (5). Q20: Are you confident to independently restore teeth using dental implants in your future practice? Q21: Will you offer dental implant therapy as a treatment option in your future practice?

Table A2. Knowledge, attitude and practice of dental interns and the differences among different groups of GPA, Gender and Age.

\begin{tabular}{|c|c|c|c|c|c|c|c|c|c|c|}
\hline \multirow{2}{*}{ Constructs } & \multirow{2}{*}{ Gender } & \multirow{2}{*}{$\mathbf{N}$} & \multirow{2}{*}{ Mean } & \multirow{2}{*}{ SD } & \multicolumn{2}{|c|}{$95 \%$ CI } & \multirow{2}{*}{ Min } & \multirow{2}{*}{$\operatorname{Max}$} & \multirow{2}{*}{$\mathbf{F}$} & \multirow{2}{*}{$\mathbf{p}$} \\
\hline & & & & & Lower & Upper & & & & \\
\hline \multirow[t]{2}{*}{ Knowledge } & Female & 132 & 9.72 & 1.38 & 9.48 & 9.96 & 5.00 & 15.00 & \multirow[t]{2}{*}{1.910} & \multirow[t]{2}{*}{0.169} \\
\hline & Male & 73 & 9.41 & 1.77 & 9.00 & 9.82 & 4.00 & 14.00 & & \\
\hline \multirow[t]{2}{*}{ Attitude } & Female & 131 & 6.67 & 0.86 & 6.52 & 6.82 & 4.00 & 8.00 & \multirow[t]{2}{*}{2.129} & \multirow[t]{2}{*}{0.146} \\
\hline & Male & 73 & 6.85 & 0.78 & 6.67 & 7.03 & 5.00 & 8.00 & & \\
\hline
\end{tabular}




\begin{tabular}{|c|c|c|c|c|c|c|c|c|c|c|}
\hline \multirow[t]{2}{*}{ Practice } & Female & 132 & 2.44 & 0.98 & 2.27 & 2.61 & 0.00 & 5.00 & \multirow[t]{2}{*}{2.579} & \multirow[t]{2}{*}{0.110} \\
\hline & Male & 73 & 2.21 & 1.03 & 1.97 & 2.45 & 0.00 & 5.00 & & \\
\hline \multirow{2}{*}{ Constructs } & \multirow{2}{*}{ Age } & \multirow{2}{*}{$\mathbf{N}$} & \multirow{2}{*}{ Mean } & \multirow{2}{*}{ SD } & \multicolumn{2}{|c|}{$95 \%$ CI } & \multirow{2}{*}{ Min } & \multirow{2}{*}{$\operatorname{Max}$} & \multirow{2}{*}{$\mathbf{F}$} & \multirow{2}{*}{$\mathbf{p}$} \\
\hline & & & & & Lower & Upper & & & & \\
\hline \multirow[t]{3}{*}{ Knowledge } & $22-24$ & 67 & 9.49 & 1.54 & 9.12 & 9.87 & 4.00 & 13.00 & \multirow[t]{3}{*}{0.462} & \multirow[t]{3}{*}{0.631} \\
\hline & $24-26$ & 131 & 9.65 & 1.51 & 9.39 & 9.91 & 5.00 & 15.00 & & \\
\hline & $26-28$ & 7 & 10.00 & 2.08 & 8.07 & 11.93 & 7.00 & 14.00 & & \\
\hline \multirow[t]{3}{*}{ Attitude } & $22-24$ & 67 & 6.63 & 0.87 & 6.42 & 6.84 & 5.00 & 8.00 & \multirow[t]{3}{*}{1.532} & \multirow[t]{3}{*}{0.219} \\
\hline & $24-26$ & 130 & 6.81 & 0.82 & 6.67 & 6.95 & 4.00 & 8.00 & & \\
\hline & $26-28$ & 7 & 6.43 & 0.79 & 5.70 & 7.16 & 6.00 & 8.00 & & \\
\hline \multirow[t]{3}{*}{ Practice } & $22-24$ & 67 & 2.25 & 1.03 & 2.00 & 2.51 & 0.00 & 5.00 & \multirow[t]{3}{*}{0.569} & \multirow[t]{3}{*}{0.567} \\
\hline & $24-26$ & 131 & 2.41 & 0.98 & 2.24 & 2.58 & 0.00 & 5.00 & & \\
\hline & $26-28$ & 7 & 2.29 & 1.25 & 1.13 & 3.45 & 0.00 & 3.00 & & \\
\hline \multirow{2}{*}{ Constructs } & \multirow{2}{*}{ GPA } & \multirow{2}{*}{$\mathbf{N}$} & \multirow{2}{*}{ Mean } & \multirow{2}{*}{ SD } & \multicolumn{2}{|c|}{$95 \%$ CI } & \multirow{2}{*}{ Min } & \multirow{2}{*}{$\operatorname{Max}$} & \multirow{2}{*}{$\mathbf{F}$} & \multirow{2}{*}{$\mathbf{p}$} \\
\hline & & & & & Lower & Upper & & & & \\
\hline Knowledge & $2.0-3.0$ & 3 & 9.00 & 1.00 & 6.52 & 11.48 & 8.00 & 10.00 & 0.333 & 0.717 \\
\hline & $3.0-4.0$ & 72 & 9.56 & 1.66 & 9.17 & 9.95 & 4.00 & 14.00 & & \\
\hline & $4.0-5.0$ & 130 & 9.65 & 1.48 & 9.40 & 9.91 & 5.00 & 15.00 & & \\
\hline Attitude & $2.0-3.0$ & 3 & 6.33 & 0.58 & 4.90 & 7.77 & 6.00 & 7.00 & 3.325 & 0.038 \\
\hline & $3.0-4.0$ & 71 & 6.55 & 0.98 & 6.32 & 6.78 & 4.00 & 8.00 & & \\
\hline & $4.0-5.0$ & 130 & 6.85 & 0.73 & 6.72 & 6.97 & 5.00 & 8.00 & & \\
\hline Practice & $2.0-3.0$ & 3 & 1.67 & 1.15 & -1.20 & 4.54 & 1.00 & 3.00 & 0.746 & 0.475 \\
\hline & $3.0-4.0$ & 72 & 2.39 & 1.03 & 2.15 & 2.63 & 0.00 & 4.00 & & \\
\hline & $4.0-5.0$ & 130 & 2.35 & 0.99 & 2.18 & 2.53 & 0.00 & 5.00 & & \\
\hline
\end{tabular}

\section{DISCUSSION}

Dental interns represent the next generation of dentists as most of them will handle patient care individually within the next few months after graduation either in their own private practice or as part of a healthcare community and their knowledge and attitudes will influence future care provided by them. Furthermore, implant therapy is an elective procedure in most cases and patients largely rely on dentists to provide them with complete information on dental implant therapy and alternative treatment options so they can make an informed choice [21]. Studies have shown that for patients, dentists are the primary source of information about dental implants [22, 23]. Therefore, the knowledge and attitudes of dental interns play a crucial role in determining whether they will be able to offer adequate information and quality dental implant therapy to their patients and this is the reason dental interns were the target sample of this study.

The purpose of this study was to assess the knowledge, attitude and practice of dental interns among different groups of age, GPA and gender. To the best of the author's knowledge, this is the first study that includes samples from many different universities in Saudi Arabia. In general, the majority of dental interns received only theoretical training in dental implants and began learning about dental implants from the $5^{\text {th }}$ year of the study or later, and a very limited number of dental interns participated in clinical trainings or any other practical trainings. Consequently, the majority of the participants $(93.2 \%)$ did not place dental implants independently during their undergraduate training. This is much different from another multicenter study done in Riyadh, Saudi Arabia, in 2017, which reported that $47.1 \%$ of dental interns had done dental implant procedures [24]. Despite the lack of clinical experience, more than half of the participants $(63.4 \%)$ are confident to independently restore teeth using dental implants in their future practice. This may be attributed to theoretical knowledge of dental implants that are acquired by the students, but interestingly, the response to this question did not differ significantly with respect to GPA. However, it did differ significantly between gender and age, with males and older interns more confident than females and other age groups, respectively.

Although several advancements have been made in the material composition of endosseous dental implants with zirconia emerging as a promising material, titanium remains the gold standard material for implant fabrication [25]. Occasionally, other metal alloys involving gold, stainless steel and cobalt have been used, but they have produced adverse clinical reactions and low success rates, which has led practitioners to avoid using these materials altogether [26]. Most participants $(80 \%)$ in this study responded correctly when asked if they knew about the primary material an implant screw is made of, i.e., titanium. Furthermore, almost all of them (94.6\%) knew that the implant body is manufactured in different designs and more than half of them (68.3\%) correctly identified that cylindrical, hollow and screw-shaped are all examples of dental implant body designs. Majority of the participants (64.4\%) also stated that case selection is the most important criterion for the success of the implant-retained restoration. This is higher than that reported by a study [27] conducted in India on dental interns, wherein the study found that $56.1 \%$ participants believed that case selection is the single biggest determinant of implant success. Studies have shown that case selection is, in fact, the most important factor for the success of dental implant therapy and most participants in the 
study correctly identified this factor [28, 29]. When asked what the biggest advantage of dental implant therapy over the fixed prosthesis is, the majority of the participants $(60 \%)$ chose to eliminate the need for adjacent tooth reduction. In another study [27], 55.4\% interns also chose the same factor. This is an important observation because even though FPDs were the treatment of choice for dentists and patients for the last few decades, survival limitations due to caries and endodontic failure of adjacent/abutment teeth have led to more practitioners turning to dental implants for restoration of partially edentulous arches [30].

Finally, many participants in this study feel the need for more theoretical, clinical and laboratory training in dental implants. This is a consequence of the earlier observation that majority of the participants never placed a single dental implant independently which clearly indicates that there is a need for more clinical training among senior dental students and dental interns and this can be achieved by introducing minimum mandatory requirements of cases with implant retained restorations to be done by students during clinical rotations.

\section{CONCLUSION}

This study demonstrates good knowledge, attitude towards dental implants but lack of practical experience. Males are more confident that females in using dental implants in their future practice as they are older interns. There is a need for introducing more clinical training in dental implants in the curriculum for senior students in order to give them hands-on experience in this treatment modality.

\section{LIMITATIONS}

One major limitation of this study was that the response rate of participants from each university was low, which made comparisons between different universities difficult because sample size from some universities was very small, which could not produce statistically accurate results. Comparisons between different universities would have provided valuable insight as to which specific universities need improvement in dental implant clinical training.

\section{ETHICS APPROVAL AND CONSENT TO PARTICIPATE}

The present research is a cross-sectional study proposed to the Institutional Review Board (IRB) of Prince Sattam bin Abdulaziz University, Saudi Arabia with IRB number PSAU2020014.

\section{HUMAN AND ANIMAL GUIDELINES}

Not applicable

\section{STANDARD FOR REPORTING}

STROBE guidelines and methodology were followed to conduct the study.

\section{CONSENT FOR PUBLICATION}

Written informed consent was obtained from each participate prior to the study.

\section{AVAILABILITY OF DATA AND MATERIALS}

The authors confirm that the data supporting the findings of this study are available within the article.

\section{FUNDING}

None.

\section{CONFLICT OF INTEREST}

The authors declare no conflicts of interest, financial or otherwise.

\section{ACKNOWLEDGEMENTS}

Declared none.

\section{REFERENCES}

[1] Palmer R. Introduction to dental implants. Br Dent J 1999; 187(3): 127-32.

[PMID: 10481363]

[2] Adell R, Eriksson B, Lekholm U, Brånemark PI, Jemt T. Long-term follow-up study of osseointegrated implants in the treatment of totally edentulous jaws. Int J Oral Maxillofac Implants 1990; 5(4): 347-59. a [PMID: 2094653]

[3] Adell R, Lekholm U, Gröndahl K, Brånemark PI, Lindström J, Jacobsson M. Reconstruction of severely resorbed edentulous maxillae using osseointegrated fixtures in immediate autogenous bone grafts. Int J Oral Maxillofac Implants 1990; 5(3): 233-46. b

[PMID: 2098327]

[4] Albrektsson T. A multicenter report on osseointegrated oral implants. J Prosthet Dent 1988; 60(1): 75-84.

[http://dx.doi.org/10.1016/0022-3913(88)90355-1] [PMID: 3042986]

[5] Lindh T, Gunne J, Tillberg A, Molin M. A meta-analysis of implants in partial edentulism. Clin Oral Implants Res 1998; 9(2): 80-90. [http://dx.doi.org/10.1034/j.1600-0501.1998.090203.x] [PMID: 9663035]

[6] Naert I, Koutsikakis G, Duyck J, Quirynen M, Jacobs R, van Steenberghe D. Biologic outcome of implant-supported restorations in the treatment of partial edentulism. part I: a longitudinal clinical evaluation. Clin Oral Implants Res 2002; 13(4): 381-9. a

[http://dx.doi.org/10.1034/j.1600-0501.2002.130406.x] [PMID: 12175375]

[7] Naert I, Koutsikakis G, Duyck J, Quirynen M, Jacobs R, van Steenberghe D. Biologic outcome of implant-supported restorations in the treatment of partial edentulism. part I: a longitudinal clinical evaluation. Clin Oral Implants Res 2002; 13(4): 381-9. b [http://dx.doi.org/10.1034/j.1600-0501.2002.130406.x] [PMID: 12175375]

[8] Jivraj S, Chee W. Rationale for dental implants. Br Dent J 2006; 200(12): 661-5.

[http://dx.doi.org/10.1038/sj.bdj.4813718] [PMID: 16799436]

[9] Grogono AL, Lancaster DM, Finger IM. Dental implants: a survey of patients' attitudes. J Prosthet Dent 1989; 62(5): 573-6. [http://dx.doi.org/10.1016/0022-3913(89)90082-6] [PMID: 2607480]

[10] Walia K, Belludi SA, Kulkarni P, Darak P, Swamy S. A comparative and a qualitative analysis of patient's motivations, expectations and satisfaction with dental implants. J Clin Diagn Res 2016; 10(4): ZC23-6.

[http://dx.doi.org/10.7860/JCDR/2016/17004.7538] [PMID: 27190945]

[11] AlKindi M, Ramalingam S, Abuhaimed A, Alkharan H. Undergraduate implant dentistry training in saudi dental schools. J Ayub Med Coll Abbottabad 2018; 30(2): 217-22.

[PMID: 29938422]

[12] Slavkin HC. Science, technology and health literacy for the $21^{\text {st }}$ century. A future for dentistry. Percy T. Phillips Memorial Lecture. N Y State Dent J 1998; 64(10): 25-8. [PMID: 9951278]

[13] Chappell RP. Dental school implant survey. Oral Implantol 1974; 5(1): 24-32. 
[PMID: 4530235]

[14] Bavitz JB. Dental implantology in U.S. dental schools. J Dent Educ 1990; 54(3): 205-6. [http://dx.doi.org/10.1002/j.0022-0337.1990.54.3.tb02402.x] [PMID: 2307756]

[15] Weintraub AM, Seckinger R, Berthold P, Weintraub GS. Predoctoral implant dentistry programs in US dental schools. J Prosthodont 1995; 4(2): 116-21.

[http://dx.doi.org/10.1111/j.1532-849X.1995.tb00326.x] [PMID: 8528440]

[16] Wilcox CW, Huebner GR, Mattson JS, Nilsson DE, Blankenau RJ. Placement and restoration of implants by predoctoral students: the Creighton experience. J Prosthodont 1997; 6(1): 61-5.

[http://dx.doi.org/10.1111/j.1532-849X.1997.tb00066.x] [PMID: 9497770]

[17] Petropoulos VC, Arbree NS, Tarnow D, et al. Teaching implant dentistry in the predoctoral curriculum: a report from the ADEA Implant Workshop's survey of deans. J Dent Educ 2006; 70(5): 580-8. [http://dx.doi.org/10.1002/j.0022-0337.2006.70.5.tb04114.x] [PMID: 16687644]

[18] Lim MV, Afsharzand Z, Rashedi B, Petropoulos VC. Predoctoral implant education in U.S. dental schools. J Prosthodont 2005; 14(1): 46-56.

[http://dx.doi.org/10.1111/j.1532-849X.2004.04047.x] [PMID: 15733135]

[19] Atashrazm P, Vallaie N, Rahnema R, Ansari H, Shahab MP. Worldwide predoctoral dental implant curriculum survey. J Dent (Tehran) 2011; 8(1): 12-8.

[PMID: 21998802]

[20] Aljohani HA, Alghamdi AST. Predoctoral dental implant education at King Abdulaziz University. Saudi Dent J 2009; 21(3): 135-8.

[http://dx.doi.org/10.1016/j.sdentj.2009.10.005] [PMID: 23960472]

[21] Zitzmann NU, Sendi P, Marinello CP. An economic evaluation of implant treatment in edentulous patients-preliminary results. Int $\mathrm{J}$ Prosthodont 2005; 18(1): 20-7.

[PMID: 15754888]

[22] Pommer B, Zechner W, Watzak G, Ulm C, Watzek G, Tepper G. Progress and trends in patients' mindset on dental implants. I: level of information, sources of information and need for patient information. Clin Oral Implants Res 2011; 22(2): 223-9.

[http://dx.doi.org/10.1111/j.1600-0501.2010.02035.x]

[PMID: 21087319]

23] Chowdhary R, Mankani N, Chandraker NK. Awareness of denta implants as a treatment choice in urban Indian populations. Int J Oral Maxillofac Implants 2010; 25(2): 305-8.

[PMID: 20369088]

[24] Ramalingam S, Habib SR, Sundar C, Dawas AB, Al-Rashed M, AlBader R. Perceptions of dental interns in Saudi Arabia toward implant placement in medically compromised patients. J Educ Health Promot 2017; 6: 104 .

[http://dx.doi.org/10.4103/jehp.jehp_68_17] [PMID: 29296605]

[25] Osman RB, Swain MV. A Critical Review of Dental Implant Materials with an Emphasis on Titanium versus Zirconia. Materials (Basel) 2015; 8(3): 932-58.

[http://dx.doi.org/10.3390/ma8030932] [PMID: 28787980]

[26] Sykaras N, Iacopino AM, Marker VA, Triplett RG, Woody RD. Implant materials, designs, and surface topographies: their effect on osseointegration. A literature review. Int J Oral Maxillofac Implants 2000; 15(5): 675-90

[PMID: 11055135]

[27] Chaudhary S, Gowda TM, Kumar TAB, Mehta DS. Knowledge and attitudes of dental interns in Karnataka state, India, regarding implants. J Dent Educ 2013; 77(10): 1365-70.

[http://dx.doi.org/10.1002/j.0022-0337.2013.77.10.tb05611.x] [PMID: 24098041]

[28] Barbosa F. Patient selection for dental implants. Part 1: data gathering and diagnosis. J Indiana Dent Assoc 2000; 79(1): 8-11. [PMID: 11314374]

[29] Sharma A, Chaudhari BK, Shrestha B, et al. Knowledge and perception about dental implants among undergraduate dental students. BDJ Open 2019; $5: 1$.

[http://dx.doi.org/10.1038/s41405-018-0009-1] [PMID: 30886741]

[30] Walton JN, Gardner FM, Agar JR. A survey of crown and fixed partial denture failures: length of service and reasons for replacement. J Prosthet Dent 1986; 56(4): 416-21.

[http://dx.doi.org/10.1016/0022-3913(86)90379-3] [PMID: 3531480]

\section{C) 2020 Alzahrani et al.}

This is an open access article distributed under the terms of the Creative Commons Attribution 4.0 International Public License (CC-BY 4.0), a copy of which is available at: https://creativecommons.org/licenses/by/4.0/legalcode. This license permits unrestricted use, distribution, and reproduction in any medium, provided the original author and source are credited. 